\title{
ESPAÇO, RELIGIÃO \& ANTROPOLOGIA: UMA LEITURA DAS FORMAS ELEMENTARES DA VIDA RELIGIOSA, DE DURKHEIM
}

\section{- RENATA DE CASTRO MENEZES ${ }^{1}$}

RESUMO: 0 TEXTO APRESENTA A DISCUSSÃO SOBRE RELIGIÃO E ESPAÇO A PARTIR DE UMA PERSPECTIVA ANTROPOLÓGICA, TOMANDO COMO FIO CONDUTOR UMA ANÁLISE DE AS FORMAS ELEMENTARES DA VIDA RELIGIOSA, DE ÉMILE DURKHEIM, TANTO EM SEU CONTEXTO DE CRIAÇÃO, NO INÍCIO DO SÉCULO XX, COMO EM SUAS POSSIBILIDADES DE APLICAÇÃO EM PESQUISAS CONTEMPORÂNEAS.

PALAVRAS CHAVES: RELIGIÃO, ESPAÇO E ANTROPOLOGIA. ESCOLA SOCIOLÓGICA FRANCESA. DURKHEIM. ESPAÇO E SOCIABILIDADE. ESPAÇO E CLASSIFICAC̦̃̃O.

Este artigo tem por objetivo trazer em cada caso estudado. Assim, defendo que uma elementos para um debate interdisciplinar sobre religião e espaço, a partir de uma experiência pessoal de trabalho na área de Antropologia. A motivação para participar do debate é a consciência de que as reflexões sobre espaço tiveram e continuam a ter peso tanto na teoria antropológica em geral, como, mais especificamente, na antropologia da religião. Nas pesquisas que realizei, com o objetivo de estudar a religião como efetivamente vivida, fazendo-se em sociedade, as análises da espacialidade de locais, de interações, de movimentos produzidos pelos agentes possibilitaram-me perceber várias coisas análise através do espaço, no espaço ou do espaço tenha um papel de destaque nos estudos antropológicos da religião, o qual deve ser estimuladoi.

Os antropólogos, por privilegiarem o trabalho de campo enquanto seu meio específico de produção de conhecimento original, têm por hábito tomar por mote suas experiências etnográficas. No caso deste artigo, o caminho seguido foi diverso: optou-se por retomar um texto clássico da disciplina - As Formas Elementares da Vida Religiosa, de Émile Durkheim (DURKHEIM, 1989 [1912]), e, a partir dele, ESPAÇO E CULTURA, UERJ, RJ, N. 32, P.30-47, JUL./DEZ. DE 2012 http://www.e-publicacoes.uerj.br/index.php/espacoecultura/ 
recortar o tema proposto, trazendo apenas na última parte do texto a experiência etnográfica da autora, a fim de demonstrar a (possível) atualidade da obra.

A escolha dessa perspectiva justifica-se por alguns motivos. Primeiro, porque o exercício interdisciplinar exige sempre um esforço de tradução de conceitos e explicitação de posições. Principalmente nas Ciências Humanas, em que as palavras que utilizamos para conceituar e interpretar o mundo social são, na maior parte dos casos, as mesmas utilizadas pelo senso comum e trazem em si o peso das pré-noções e das práticas discursivas em que são postas em circulação no dia a dia. Muitas vezes os pesquisadores acreditam estar falando das mesmas coisas, por usarem as mesmas palavras-chave, mas quando elas operam como conceitos em tradições disciplinares distintas, com grades de leitura diferenciadas, eles podem na verdade estar falando de coisas muito diferentes. Assim, retornar à fonte de algumas ideias que contribuíram para fundar a pesquisa social pode servir para estabelecer uma plataforma de diálogo numa base mais precisa. É o caso da retomada aqui da obra de Durkheim e de suas discussões fundamentais sobre o sagrado.

Um segundo motivo para a escolha desse texto clássico é a celebração de seu centenário. Obra escrita em 1912, As Formas Elementares foi comentada e escrutinada em vários encontros e seminários ao longo do último ano e um dos objetivos deste trabalho é contribuir, ainda que tardiamente, com as comemorações. Mas um centenário pode ser celebrado de diversas maneiras e aqui o que se quer não é proceder a algum tipo de reverência acrítica ou de culto a um herói fundador (ALEXANDER, 1999, p. 27). O que se pretende é, a partir da análise do trabalho, reconhecer nele perspectivas gerativasii, isto é, tratá-lo como conhecimento capaz de gerar mais conhecimento.

Assumida essa forma de tratamento dos clássicos ${ }^{\mathrm{iii}}$, pretende-se realizar uma revisita ao texto de Durkheim em torno de dois eixos, que correspondem a partes do artigo: o primeiro eixo é o de sua inserção no contexto em que foi produzido, reconhecendo sua importância histórica e valorizando sua criatividade dentro de um conjunto de trabalhos contemporâneos onde alcançou distinção. Nessa parte proceder-se-á também a uma apresentação do trabalho.

O segundo eixo é o de sua possível atualidade, como um texto que ainda fornece soluções interessantes para o arranjo de dados de pesquisas atuais, dando pistas para a formulação de novos problemas. Nessa parte serão acionadas minhas experiências de pesquisa em uma festa popular da cidade do Rio de Janeiro, a Festa da Penha, como um exemplo concreto em que as perspectivas durkheimianas sobre sagrado, profano e espaço foram utilizadas para entender determinadas formas de construção de sacralidade através da ocupação do espaço ${ }^{\text {iv }}$. Introduzindo os dois eixos, há uma breve apresentação do contexto de surgimento da Antropologia enquanto uma ciência do século XIX, com referências ao peso da temática da religião em sua constituição.

\section{AS ORIGENS DA ANTROPOLOGIA E A TEMÁTICA DA RELIGIÃO}


O que hoje é conhecido como Antropologia Social (nomenclatura da tradição britânica), Antropologia Cultural (tradição norteamericana) ou Etnologia (tradição francesa) é, na verdade, uma disciplina surgida no século XIX no conjunto das Ciências Humanas, num contexto geral em que outras disciplinas também se configuravam ou reconfiguravam, definindo seus campos de atuação. Nesse contexto, caberia à Antropologia estudar as origens da Humanidade, ou seja, as sociedades primitivas, isto é, os povos sem escrita que, pela concepção evolucionista do período, seriam povos pré-históricos, verdadeiras sobrevivências do passado no tempo presente, por não terem evoluído.

Como ciência humana, a Antropologia teria que dar conta do que parecia ser um dilema, o fato de que a espécie humana, isto é, uma mesma espécie animal, apresentava uma grande variação de hábitos e de comportamento em todo o planeta, enquanto que as demais espécies apresentavam padrões bem mais restritos. Para encontrar suas respostas, a Antropologia se contrapôs a dois determinismos, o determinismo racial e o determinismo geográfico, através do conceito de cultura. Contra a ideia do comportamento humano determinado por características raciais ou pelo meio-ambiente, ela vai defender a variação cultural como chave explicativa da diversidade humana. Inicialmente, Cultura - com inicial maiúscula e no singular assinalando a crença em um desenvolvimento evolutivo unilinear da Humanidade, tal como formulado por Edward Tylor (1832-1917), em 1871, em seu livro Primitive Culture.
"Cultura ou civilização (...) é esse todo complexo que inclui conhecimento, crença, arte, leis, moral, costumes e quaisquer outras capacidades e hábitos adquiridos pelo homem enquanto membro da sociedade." (TYLOR, 2010 [1871], p. 1).

Nessa perspectiva, as diferenças entre os povos corresponderiam a diferentes estágios evolutivos da humanidade. Porém, um pouco mais tarde, a partir dos trabalhos de Franz Boas (1858$1942)^{v}$, consolidador da antropologia norteamericana, essa abordagem sofrerá uma transformação sutil, mas radical. $\mathrm{O}$ termo cultura passará a ser utilizado no plural, culturas, justificando-se as variações entre os grupos humanos pelas particularidades históricas de cada um deles e defendendo-se a concepção de desenvolvimentos multilineares (LAPLANTINE, 1987). Para a Antropologia, a cultura operaria como um tipo de "mecanismo adaptativo da espécie humana" (por oposição ao instinto dos demais animais), e sua variação de grupo a grupo explicaria a plasticidade do comportamento da espécie (LARAIA, 1989).

Nesse quadro de referências, que vai se compondo do segundo quarto do século XIX até mais ou menos o final da $1^{\mathrm{a}}$. Guerra Mundial (1918), lei, parentesco e religião serão os temas principais a que se dedicarão os antropólogos. Posteriormente, ao longo da história da disciplina, o peso de cada um desses temas será desigual - o 
parentesco será o tema antropológico por excelência, no qual a Antropologia exibirá de forma mais evidente sua cientificidade, constituindo uma especialidade; o interesse pela religião e pela lei passará por momentos de maior e menor intensidade.

Como é a religião o foco de interesse do artigo, vamos nos fixar nela. Religião era um tema "quente" no século XIX. Aquele foi um momento de intensificação das relações entre o Ocidente e "os outros", graças à expansão Imperialista da Europa e dos EUA sobre a Ásia, a África e a Oceania, e a religião foi um dos principais instrumentos para pensar a diferença entre os povos. Debates sobre a existência ou não de religião em determinados povos, sobre a história evolutiva das religiões e sua relação com o desenvolvimento do pensamento humano, tentativas de estabelecer uma definição mínima de religião universalmente aplicável são temas recorrentes naquele período, tendo comumente todos eles o Cristianismo como o lugar de ponto de partida, ou de chegada, das análises. Obviamente essas questões não interessam apenas à Antropologia, e ela disputará as interpretações sobre religião com outros campos do saber, como a Teologia, as Ciências da Religião, a História Comparada das Religiões, etc.

Os contatos com Ásia, África e Oceania trouxeram uma massa de dados empíricos ao Ocidente. Os materiais escritos que vêm do Oriente se tornam acessíveis à compreensão ocidental graças ao desenvolvimento da linguística, notadamente da filologia comparada, o que amplia o espectro das religiões conhecidas. Essa explosão de dados provoca a reorganização dos esquemas de pensamento, e trava-se uma ampla discussão sobre como classificar a variedade ora descoberta, como demonstra Jonathan Z. Smith: seriam as diversas religiões gêneros de uma espécie geral, uma religião genérica? E se empiricamente só temos contato com a variedade de espécies, como recompor essa religião genérica original? E a partir de quais princípios classificar a variedade que se apresenta? (SMITH, 1998).

A historiadora Tomoko Masuzawa (MASUZAWA, 2005) dedicou seu livro The Invention of World Religions à compreensão das novas taxionomias religiosas produzidas por europeus no século XIX. Nele, a autora demonstra como as classificações ensaiadas fizeram surgir a ideia de grandes religiões mundiais, que seriam agrupadas a partir de uma combinação oscilante de critérios geográficos, históricos, linguísticos e étnico-racializantes. As grandes religiões corresponderiam assim a grandes civilizações. Uma das classificações correntes é a fórmula ternária religiões do Oriente Próximo (Judaísmo, Cristianismo, Islã) / religiốes do Sul da Ásia (Hinduísmo, Budismo, Zoroastrismo, Jainismo) / religiôes do Extremo Oriente (Confucionismo, Taoísmo, Xintoísmo). As divisões desse esquema seriam correlatas ao que se considerava à época como as três grandes famílias linguísticas: Semitas, Arianos, Turanianos. Já as expressões religiosas de sociedades tribais, subsaarianas ou da Oceania seriam consideradas menores, tanto por seu raio de extensão, como por serem vistas como indício de formas mais simplórias de organização social e de pensamento, formas sem escrita e, portanto, pré- 
históricas, as quais tenderiam a desaparecer no processo de "colonização cultural" que o progresso imperialista traria.

A preocupação da autora, no entanto, é a de demonstrar como essas classificações não se relacionam apenas ao avanço científico, ao progresso do conhecimento, mas estão relacionadas a um processo mais amplo de reconstrução da identidade europeia num contexto imperialista, de valorização do progresso, da racionalidade e da secularização. Por um lado, as novas classificações estão associadas à ampliação do passado europeu, agregando às suas origens semíticas e gregas, questões sobre sua origem indo-européia. Por outro lado, elas permitem que os europeus pensem seu futuro, reinterpretando sua herança cristã nesse novo contexto. A autora defende ainda que classificações como essas, apesar de apresentarem um esquema tripartite, ocultam que o que está verdadeiramente em jogo é a distinção entre o "Ocidente" e o resto, pois os critérios de demarcação de blocos são articulados a partir do ponto de vista europeu ocidental. No final, o que resta é a imagem do Ocidente como o local do progresso e do futuro, já o Oriente, apesar de rico em tradições, representa o local do passado e da história estagnada. Quanto a africanos e demais tradições aborígenes australianas, caberlhes-ia o rótulo de povos sem história, com religiões primitivas, configurando-se quase como um elo perdido da humanidade.

Note-se que os conceitos utilizados nas análises, como rito, idolatria, fetiche, sacrifício, cerimônia, magia, festas, costumes, foram criados ainda entre os séculos XV e XVII, período de descobrimento e colonização das Américas, no qual houve longos debates sobre o pertencimento ou não das populações nativas aos limites da humanidade. Nesse quadro, foram ensejados esforços para identificar elementos religiosos mínimos para os quais um novo léxico foi produzido, ou redefinido. No entanto, esses conceitos, que chegaram ao século XIX e continuam em operação nos dias de hoje, eram totalmente exteriores aos povos aos quais eles eram aplicados, isto é, foram forjados a partir de categorias construídas pelo próprio Ocidente e foram produzidos num contexto de missão e de colonização, em que a intenção era reduzir as diferenças através da absorção de todos ao Cristianismo (POMPA, 2006).

\section{AS FORMAS ELEMENTARES NOS DEBATES SOBRE RELIGIÃO}

Foi portanto navegando nessa complexidade em torno da religião que os primeiros antropólogos se posicionaram, tentando construir um espaço próprio de análise voltado às religiões primitivas, mas contando para isso com conceitos, taxionomias e debates produzidos em contexto colonial. E nesse jogo de combinações e demarcações surge em 1912 uma obra seminal para a Antropologia quanto ao estudo das religiões: $A s$ Formas Elementares da Vida Religiosa, de Émile Durkheim. Seminal porque, embora não possa mais ser incorporada em sua totalidade, trouxe perspectivas que até hoje continuam motivando nossos trabalhos.

Durkheim fizera anteriormente obras sobre a divisão social do trabalho (1893), as regras 
do método sociológico (1895) e o suicídio (1897). Mas nas Formas Elementares, que viria a ser seu último livro publicado em vida, ele focaliza a religião nas sociedades primitivas. É um deslocamento assinalando que, após décadas de trabalho com pesquisadores como Marcel Mauss, Henri Hubert e Robert Hertz, que gravitavam em torno do periódico Année Sociologique, que para muitos constitui a Escola Francesa de Sociologia (ou Escola Sociológica Francesa), Durkheim está seriamente convencido da importância crucial da religião na manutenção do vínculo social, o que é sua grande preocupação. Em Formas Elementares, Durkheim quer estudar a "forma elementar" da religião numa sociedade primitiva porque acredita que nela será analiticamente mais controlável, mais fácil de visualizar, sem as variáveis vigentes em sociedades mais complexas. A noção de "elementar" assume na obra um sentido ambíguo, que ora se refere à origem histórica, ora à origem lógica da religião, mas o importante é que o autor defende que a compreensão obtida na sociedade primitiva servirá para entender toda e qualquer forma de religião, em toda e qualquer forma de sociedade. Nota-se assim que, apesar de um viés evolucionista, não se postula uma descontinuidade entre povos primitivos e civilizados, pois é pelas sociedades simples que se pretende entender as complexas.

Dentro dos debates sobre a origem da religião que marcaram sua época, Durkheim considera como a forma elementar o totemismo das tribos australianas ${ }^{\mathrm{vi}}$, isto é, a crença numa consubstancialidade entre os seres humanos, os animais e as plantas, com homologias entre o reino natural e a organização social desses grupos em clãs e fratrias.

Se o debate sobre religião era um campo minado, para ingressar nele Durkheim beneficiouse das contribuições de seus colegas que estavam há décadas tentando promover uma espécie de "limpeza de terreno teórica", tentando redefinir os principais conceitos das ciências sociais, e que aparecem nas notas e referências bibliográficas das Formas Elementares. Assim, os trabalhos de Hubert e Mauss sobre o sacrifício e a magia (HUBERT; MAUSS, 2005 [1899]; 2003 [19021903]), de Hubert, sobre o tempo (HUBERT, 1929 [1905]), de Hertz sobre a preeminência da mão direita (HERTZ, 1980 [1909]), e de Mauss sobre a prece (MAUSS, 1968 [1909]), dentre outros, forneceram a Durkheim os alicerces para a montagem de seu grande edifício. Trata-se, portanto, de uma obra com uma forte dimensão coletiva, o que é uma das razões de sua relevância, pois é uma demonstração explícita do poder de colaboração e do acúmulo de conhecimento nas Ciências Sociais.

A preocupação com o controle das prénoções, fundamental na metodologia durkheimiana, vai influir na estrutura das Formas Elementares, que terá três partes, ou três livros: o primeiro tratará de "questões preliminares", em que o autor se posiciona diante das diferentes teorias existentes. É do contraponto com outros autores que surgem os conceitos básicos de sua sociologia da religião. Por exemplo, quanto às religiões verdadeiras e religiões falsas, Durkheim afirma que para o cientista social essa questão não se coloca, pois para ele todas as religiões são 
"verdadeiras" enquanto fatos sociais: elas provocam efeitos sociais, articulam relações sociais, e é essa dimensão inegável da religião como fato social que lhe interessará analisar. Nos debates sobre a anterioridade da magia em relação à religião na evolução do pensamento humano, Durkheim opta por não postular um encadeamento entre elas, mas um paralelismo relacionado à noção de Igreja: a religião envolve uma igreja, isto é, uma comunidade moral formada por todos os crentes da mesma fé, fiéis e sacerdotes, que comungam em concepções e práticas sobre o mundo sagrado e suas relações com o mundo profano, enquanto a magia não envolve uma comunidade, mas uma relação de clientela entre o mago e aquele que procura seu atendimento.

E, finalmente, quanto a uma definição generalizável de religião, Durkheim propõe uma fórmula que se tornará clássica:

\section{(...) [O fenômeno religioso]} pressupõe uma divisão bipartida do universo conhecido e conhecível em dois gêneros que compreendem tudo o que existe, mas que se excluem radicalmente. As coisas sagradas são aquelas que os interditos protegem e isolam; as coisas profanas, aquelas às quais esses interditos se aplicam e que devem permanecer à distância das primeiras. As crenças religiosas são representações que exprimem a natureza das coisas sagradas e as relações que essas mantêm entre si e com as coisas profanas. Enfim, os ritos são regras de comportamento que prescrevem como o homem deve se comportar com as coisas sagradas. (...) Quando certo número de coisas sagradas mantém entre si relações de coordenação e de subordinação de maneira a formar sistema com certa unidade, que, entretanto, não entra em nenhum outro sistema do mesmo gênero, o conjunto das crenças e dos ritos correspondentes constitui religião. (DURKHEIM, 1989 [1912], p. 72-73).

Vê-se que para Durkheim a religião envolve uma classificação das coisas em sagradas e profanas, dividindo o mundo em dois domínios. Mas é importante ressaltar que sua definição não substantiva nem congela o sagrado: qualquer coisa pode ser sagrada, desde que o grupo a destaque e a interdite do profano. A religião definir-se-ia assim por uma oposição sagrado X profano, de conteúdo não pré-definido, atualizável em cada contexto. Só que onde a oposição se estabelece, uma hierarquia se consolida: o sagrado é visto como superior e o profano, como inferior (mesmo que haja graus diferentes de inferioridade), e essa hierarquia opera como um princípio classificador. Enfatizo esse ponto, pois muitas vezes lemos em manuais 
que a sociologia da religião de Durkheim é uma sociologia do sagrado. Mas na verdade, ela é uma sociologia calcada em uma relação de oposição, da oposição entre sagrado e profano, dois termos definidos relacionalmente, que não correspondem à visão maniqueísta de bem e mal (o sagrado pode aterrorizar e destruir). Nada a meu ver, mais atual.

$$
\text { Essa definição de religião estará }
$$
diretamente relacionada à estrutura do segundo e terceiro livros, que se intitulam, respectivamente, "crenças elementares" e "as principais atitudes rituais". Esses títulos nos levam a perceber que Durkheim partilhava da definição proposta por William Robertson Smith (1846-1894) em seu livro The Religion of the Semites (SMITH, 1972 [1889]), e consagrada até hoje, da religião como um conjunto de crenças e práticas, de mitos e ritos, de representações e ações. E, talvez, para equilibrar o peso que James Frazer (1854-1941) havia atribuído aos mitos, em sua obra mundialmente consagrada, $O$ Ramo Dourado (FRAZER, 1978 [1890-1915]) ${ }^{\mathrm{vii}}$, Durkheim vai enfatizar a importância dos ritos. Segundo o autor, nos ritos, ou cerimônias de culto aos emblemas totêmicos, será produzida uma "efervescência", um conjunto de emoções e sentimentos em uníssono que permitirão que o membro de uma sociedade se sinta pertencente a um todo mais amplo, que o ultrapassa e o ergue para além de si mesmo, infundindo-lhe um profundo sentimento moral. E é sobre essa capacidade da religião, de produzir uma sensação parte-todo, que repousará o vinculo social: através dos rituais, a sociedade se faz ver e sentir aos seus membros, hipostasiando-se, isto é, ganhando concretude, tornando-se palpável. Religião, emoção e social conformam assim uma espécie de articulação inescapável.

Durkheim retoma e amplia aqui ideias do artigo Algumas formas primitivas de classificação que escreveu com Marcel Mauss em 1903 (DURKHEIM; MAUSS, 1981[1903]). Trata-se de um texto em que se encontram suas primeiras associações entre a classificação totêmica e a organização social, a formação de grupos e a relação entre ambas bem como a classificação do pensamento, a forma de ver o mundo. Para Durkheim, a experiência religiosa envolve a experimentação da oposição sagrado/ profano e servirá de base para a divisão dos grupos humanos e o estabelecimento de relações entre eles e desses com a natureza e o espaço ao seu redor. Isso porque a experiência religiosa será a fonte das categorias sociológicas, mas também das categorias lógicas - como tempo, espaço, para a classificação do universo

Nota-se desse ponto um enriquecimento da abordagem durkheimiana, a guinada de uma análise estritamente sociológica para uma análise também simbólica. Esse é outro elemento de relevância das Formas Elementares. A obra pretende tratar da importância da religião na manutenção do vínculo social. Mas isso se dá tanto do ponto de vista sociológico - criação de laços, produção de sentimentos que geram noção de pertencimento, criação de igrejas, isto é, de comunidades morais que partilham das mesmas crenças e realizam práticas em conjunto - como lógico. Tanto na introdução como na conclusão de As Formas Elementares fica evidente que se trata 
de uma obra de sociologia da religião, mas também de sociologia do conhecimento, afirmando o peso do religioso na produção e reprodução de representações coletivas, seu papel na construção das categorias do entendimento humano. A oposição sagrado/profano oferece um princípio classificador hierarquizante, capaz de estabelecer diferenças qualitativas entre elementos que, de outra forma, seriam percebidos como contínuos. É a função classificatória, segundo Durkheim, oriunda do social, que the conferirá as coordenadas, e é a religião a base sociológica/lógica da classificação. Isso operaria também quanto à percepção do espaço: a clivagem entre espaços sagrados e espaços profanos estabelecerá uma hierarquia qualitativa entre áreas que de outra forma seriam percebidas como contínuas. Essa capacidade de instaurar a diferença fará com que o espaço seja social e religiosamente construído.

\section{AS FORMAS ELEMENTARESNA FESTA DA} PENHA

Chegamos então à demonstração da atualidade da abordagem durkheimiana a partir de sua aplicação em pesquisas contemporâneas. Em 1996, defendi uma dissertação de mestrado sobre a Festa da Penha, uma festa popular celebrada em honra a Nossa Senhora da Penha em outubro, no subúrbio da cidade do Rio de Janeiro de mesmo nome, há cerca de trezentos anos. Estudo este que está sendo atualizado a partir de uma ida a campo em 2011 (MENEZES, 1996; 2012).

Entre 1992 e 1994, quando realizei a primeira pesquisa, a Festa da Penha atraía milhares de pessoas, embora com peso aparentemente maior no passado do que no presente viii. Por tratarse de uma festa antiga, foi possível acompanhar na literatura suas transformações históricas: a festa teria começado nas primeiras décadas do século XVIII, em torno de uma imagem de Nossa Senhora, considerada milagrosa, localizada em uma ermida no alto de um penhasco, em uma fazenda. A fama da santa foi atraindo romeiros para visitá-la e celebrá-la; fazendo com que a fazenda fosse doada a uma Irmandade em sua honra e que, no século XIX, a festa tivesse se tornado marco importante do calendário da cidade, uma romaria à zona rural da qual participava cerca um terço da população carioca, à qual se ia com muito sacrifico, de barco, trem, carroça.

Na passagem do século XIX para o XX, devido à abolição da escravatura e à expansão da vida urbana (que torna o acesso à região mais fácil), a Festa da Penha vai ser integrada ao circuito da "Pequena África" no Rio de Janeiro, isto é, vai se tornar um dos lugares de encontro da comunidade negra, onde sambas eram lançados antes do advento do rádio e onde as "tias baianas" armavam seus tabuleiros. Com o bairro se tornando parte da zona suburbana do Rio, a festa se torna um importante espaço de lazer para as famílias da região. Na década de 1990, a festa tornara-se "suburbana". Embora houvesse ainda romeiros de várias partes do país presentes, a maior parte de seus participantes era oriunda da região da Leopoldina. Nota-se nesse breve sumário histórico um primeiro conjunto de relações espaciais que marca a configuração da festa ao longo dos anos: as oposições "próximo $\mathrm{X}$ 
distante", " centro X periferia" vão se rearticulando e promovendo ressignificações nos sentidos da celebração ${ }^{\text {ix }}$.

A Festa da Penha, que se estende por todos os finais de semana de outubro e pelo primeiro de novembro, compreende uma série de cerimônias religiosas (novena preparatória, procissões de abertura e encerramento, missas, bênçãos, ladainhas, rezas do Rosário, coroação de Nossa Senhora, etc), mas também festejos e atrações, que envolvem comida e bebida, barracas de jogo, brinquedos de parque de diversão, shows de música popular, bandas folclóricas; e ainda barracas de lembranças, de artesanato, de roupas, de cunho religioso ou não, que dão ao evento um certo caráter de feira. Tudo isso acontece simultaneamente, num movimento constante. E porque as festas são como diria Marcel Mauss ${ }^{\mathrm{x}}$, "fatos sociais totais", a análise da espacialidade serviu-me como um fio condutor para ordenar aquilo que me parecia, nas primeiras idas a campo, um verdadeiro caos.

O espaço de uma festa pode ser abordado de uma forma mais óbvia, a partir das distinções entre a organização espacial durante o período da celebração e sua organização cotidiana. Trata-se de algo óbvio porque essas diferenças estão sempre presentes em qualquer festa popular. Mas, justamente por essa onipresença, é preciso ver como isso acontece em cada caso concreto, ou seja, qual o reordenamento espacial provocado por cada uma delas, considerando ainda que, do ponto de vista nativo, isto é, para os agentes envolvidos com o evento, um dos indicadores do sucesso de uma festa é sua capacidade de espraiamento, o volume de gente que é capaz de atrair, a extensão que consegue alcançar.

No caso da Penha, nos anos 1990, o "território da festa", ou seja, a área mobilizada pela celebração envolvia não apenas a Igreja de Nossa Senhora da Penha, mas daí se irradiava, espalhando-se pelas ruas do bairro, envolvendo terrenos de regime de propriedade distinto. Seu "centro" estava na Igreja, pertencente à Irmandade da Penha, que é a promotora da festa, mas ela também se desenvolvia pelas ruas do bairro, vias públicas, controladas pelo Estado. No croqui abaixo, vemos uma espécie de corte lateral do percurso que um visitante tem que fazer para chegar até a santa em seu altar: partindo do Largo da Penha (1), via pública, o fiel deverá cruzar os portões do Parque da Penha (a), que assinalam o ingresso nos terrenos pertencentes à Irmandade, proprietária do templo e de seu entorno, subir em aclive pela estrada da Penha (2), chegar aos portões do Santuário da Penha (b), depois subir uma combinação de escadas e ladeiras, conhecida pelos frequentadores como "o trecho mais difícil" (3), até chegar a um segundo portão do Santuário (c), que dá acesso a uma parte plana, chamada de Largo dos Romeiros (4), onde estão os prédios da Irmandade, a loja de souvenirs, um Museu, a sala de milagres, etc. Daí, há um segundo lance de escadas, que miticamente se diz ter 365 degraus (5) e que leva ao topo de um penhasco (penha), onde se localiza a igreja (6).

Figura 1: A subida até a santa. Fonte: MENEZES, 1996: 112b. 


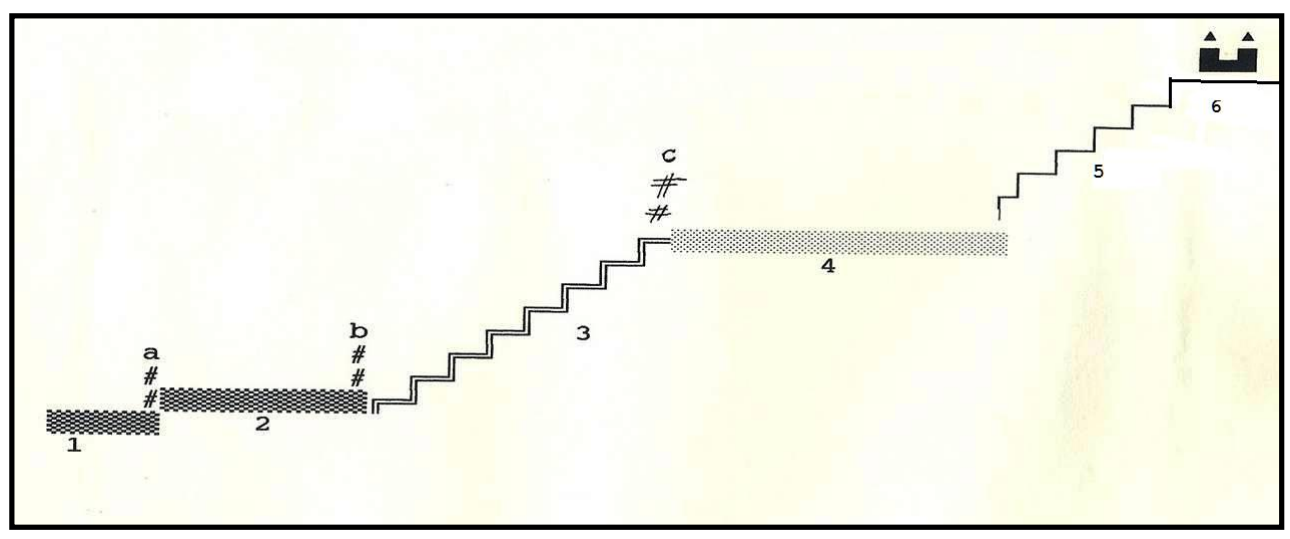

Da análise do percurso, pode-se notar que a chegada até a santa se dá num movimento cada vez mais para cima. E, como o final da subida só é atingido após a transposição de três portões, que marcam uma inclusão cada vez maior do devoto no Santuário, o movimento é também cada vez mais para dentro do terreno da Irmandade. Assim, a entrada no "Parque da Penha" (a) assinala o ingresso nos territórios da Irmandade, que tem dentro de si o Santuário, que por usa vez engloba o Largo dos Romeiros e a Igreja. Do lado de fora, no Largo da Penha e ruas adjacentes (1), a festa foge da alçada da Irmandade - qualquer barraca, qualquer atividade que lá se desenrole passa a ser gerida pelo poder público (de forma mais específica, pela Região Administrativa, órgão municipal que gerencia a parte externa da festa). Esse limite de competência foi enunciado pelo coordenador dos festejos em entrevista de 18/10/1992: "do portão para fora, não tem nada a ver com a Irmandade, é da prefeitura".

A impressão que tive durante o trabalho de campo, ao realizar a caminhada várias vezes, é que a série de "passagens" que realizava, do ponto do ônibus ao topo do rochedo, marcava não só a transição do mundo cotidiano para o mundo da festa, mas, como leitora de Durkheim, do profano ao sagrado. Minha impressão parecia corroborada por depoimentos de campo e por referências bibliográficas, que identificam no evento uma dimensão dual ao combinar devoção (à santa) e diversão (dos visitantes e dos organizadores) como suas partes constitutivas:

Ao lado da pureza do culto mantido tradicionalmente pela V. Irmandade, os festejos populares desenvolveram-se no sopé da colina e no arraial, sempre com inúmeras atrações: leilões de prendas, bandas de música e conjuntos musicais se exibindo para o povo (VENERÁVEL IRMANDADE DA PENHA, apud MENEZES, 1986, p. 94).

A Festa da Penha possui dois aspectos perfeitamente diferenciados: um deles é o sagrado, a festa dos penitentes. 
(...) O outro aspecto da festa $\operatorname{er}(\ldots)$ é francamente profano (....). As duas partes da festa, a sagrada, representada pelos penitentes, irmandades, padres e beatas; e a profana, representada pelo pessoal da Cidade Nova da Central do Brasil, os forjadores de samba, na verdade formam uma só. Mesmo o pessoal da Cidade Nova (...) iam prestar [sic] suas homenagens à santa, no alto da pedra" (FRIAS, 1997, apud MENEZES, 1986, p. 95)

Em entrevista com um membro da Irmandade, a diferença também apareceu, quando ele atribuiu dois lados à Festa da Penha, o folclórico e o religioso:

Olha, a Festa da Penha tem duas partes, né? A parte religiosa e a parte folclórica, certo? (...) Antes era o Sebastião, coitado, que faleceu, e que tomava conta disso. Ele levava artistas populares lá para baixo, levava shows, festa junina até, também, durante o ano - mas por conta dele, lá embaixo, não tinha nada a ver com a Irmandade lá em cima, entende? (Hélio, entrevista em 22/10/92).
E na entrevista de Glória, uma barraqueira "lá de cima", a dualidade novamente aparece:

Lá embaixo é o povão. Não ficaria lá nem que me pagassem. Aqui em cima é um outro ambiente, os irmãos da Igreja estão toda hora perguntando se está tudo $\mathrm{OK}$, se está vendendo bem, se precisa de alguma coisa. Há médico, policiamento. Lá embaixo, é uma desorganização (entrevista, 31/10/1993).

A distinção entre profano e sagrado parecia coincidir com a distinção morfológica entre o sopé do morro e o topo do rochedo, num rebatimento espacial perfeito, aparecendo como "natural", o que a tornaria mais facilmente sujeita à reificação: em cima, estava o sagrado, embaixo, o profano. Essa oposição "em cima" X "embaixo" associava-se à oposição já mencionada, "dentro $\mathrm{X}$ fora", e ambas combinadas relacionam-se diretamente a um princípio de organização espacial que a Irmandade da Penha tentava imprimir ao evento: quanto mais para dentro e mais para cima, mais sagrado; quanto mais para fora e mais para baixo, mais profano. Essa concepção da sacralidade estava numa razão diretamente proporcional ao grau de controle exercido pela Irmandade sobre os sucessivos espaços.

Por outro lado, a dualidade perfeitamente demarcada entre em cima $\mathrm{X}$ em baixo e dentro $\mathrm{X}$ fora me parecia mais um modelo ideal do que aquilo que era concretamente percebido em ESPAÇO E CULTURA, UERJ, RJ, N. 32, P.30-47, JUL./DEZ. DE 2012 http://www.e-publicacoes.uerj.br/index.php/espacoecultura/ 
campo, pois a música, o canto, a dança, a comida, a bebida, o comércio de objetos estavam aparentemente presentes em todos os espaços da festa. Porém, aos poucos fui percebendo que, apesar de sua onipresença, os espaços não eram do mesmo tipo, ou não se davam da mesma forma em todos os lugares da festa. Cada um desses elementos é marcado por uma grande diversidade interna que não é aleatória, mas é estabelecida pela Irmandade da Penha, através do controle de horários de fechamento dos portões, do tipo de música autorizado ou previsto em cada lugar, dos tipos de barracas e de produtos vendidos por elas. Essas diferenças socialmente construídas contribuíam para produzir a sensação de aproximação do sagrado (e, num certo sentido, o próprio sagrado).

Como já visto, o primeiro portão transposto para ingressar na festa (a) marca a separação entre uma área pública - as ruas da Penha, controladas pela Prefeitura - e o território da Irmandade. Assim, se o lado de fora da festa "não tem nada a ver com a Igreja", é nele que se instaura, ao menos do ponto de vista da Irmandade, o profano em sua forma mais livre, conquanto alheio a qualquer forma de controle "religioso". Não há hora de fechar, pode haver pagode até o amanhecer, as barracas têm formatos variados e é a região administrativa que conduz o processo de seleção dos barraqueiros. Para essa parte, a Irmandade relega práticas que possam ser vistas como um risco à catolicidade do evento, mantendo-as simultaneamente fora e parte da festa.
Já no interior do terreno da Irmandade, uma primeira passagem entre as duas partes da festa - a sagrada e a profana - estaria assinalada pelo segundo portão (b), que marca a entrada do devoto no Santuário, e dá acesso para a primeira grande subida, o trecho mais difícil. Este representaria um espaço de purificação, não só por ser um trecho em que a dimensão sacrificial é acentuada, pela dificuldade da subida, como também por ser um trecho em que o comércio é interditado, o que seria uma tentativa de expurgo do profano: apenas mendicantes podem permanecer lá, o que remete à prática tradicional cristã da caridade.

No entanto, ao transpormos o terceiro portão (c) e adentrarmos no Santuário, vemos que "lá em cima" há também uma oposicão espacial entre uma área plana (o Largo dos Romeiros e a Irmandade) e uma área íngreme (a Escadaria com a igreja no topo do rochedo). Nesse nível teríamos, na parte plana, vendedores, músicos, dançarinos, consumidores. Haveria também uma subida expiatória, a escadaria de 365 degraus. E por fim, no topo do penhasco, haveria a Igreja com a imagem da santa, representando o sagrado em seu ponto mais elevado. Nota-se então que se reproduziria, em outra escala, a oposição "em cima X embaixo e sagrado / profano", numa homologia com a oposição identificada anteriormente, o que causa a impressão de "contradição" entre o modelo dual da festa, que dizia que o profano estava embaixo e o sagrado, em cima. Porém, uma homologia entre espaços não significa uma sinonímia. Se ao transpormos o terceiro portão, encontrarmos novamente o profano, no sentido de 
que há novamente barracas, música, canto, dança, o profano do Largo dos Romeiros não é o mesmo profano do Largo da Penha: é, no meu entender, um outro profano, um profano depurado, conquanto ligado diretamente à Irmandade, o que garantiria sua submissão às diretrizes de conduta mais rígidas por ela estabelecidas.

É no Largo dos Romeiros que permanecem as pessoas mais religiosas, ou que desfrutam de algum tipo de intimidade com a festa e a Irmandade, no mínimo por serem frequentadoras assíduas. Os vendedores que atuam nesse nível também não são os mesmos que atuam no comércio lá embaixo: a venda de comida e bebidas é efetuada exclusivamente pelo dono do bar, que detém o ponto há anos, ou por voluntários católicos, com as camisetas de seus movimentos religiosos; os ex-votos e as lembranças são vendidos diretamente pela Irmandade; as barracas de objetos são de artesãos e estão lá porque sua coordenadora possui relações pessoais com um membro da Irmandade. A música é acústica, encontra-se "domada nos coretos", através de bandas convidadas, ou aparece em aspectos "folclóricos", tocada por um rancho de portugueses.

O que vemos é que, embora o percurso represente uma passagem do profano ao sagrado ao aproximar o devoto de sua santa, em nenhum momento um dos dois termos da oposição é completamente excluído. Na verdade, percebe-se que a oposição entre profano e sagrado se refrata nos vários planos da festa, existindo como que uma filtragem: quanto mais próximos estamos do alto do penhasco, maior é o controle da Irmandade, e maiores são os limites impostos às atitudes dos devotos entendidas por ela como profanas ou profanadoras. Assim, ainda que ambos sejam constitutivos da festa, e sua oposição se reproduza em todos os seus níveis, a Irmandade precisa manter o profano sob controle, dentro de certos limites, a fim de que este não contamine o sagrado. Assim, poderíamos redefinir os espaços da festa em termos de um jogo de oposições entre sagrado e profano que comporta gradações e que envolve as oposições em cima $\mathrm{X}$ embaixo; dentro $\mathrm{X}$ fora.

Figura 2: A oposição sagrado / profano ao longo da Festa da Penha. Fonte: Menezes, 1996, p.115b. 


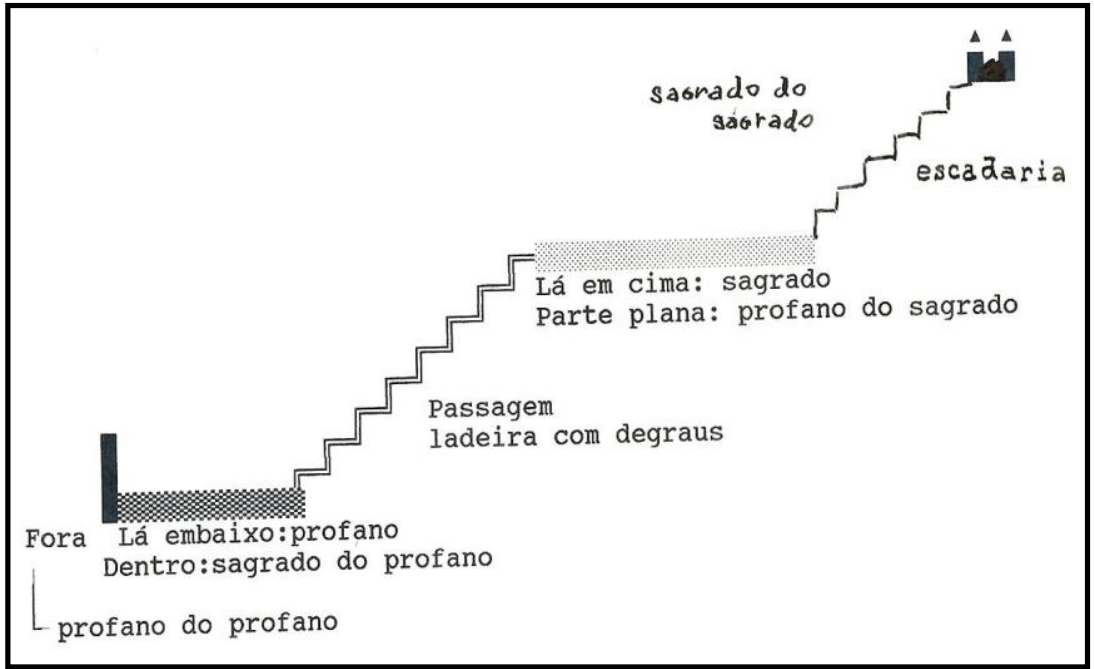

Fica evidente, como proposto por Durkheim, que a definição do sagrado se dá de forma relacional, por uma oposição fundante com o profano. Ou seja, para que o sagrado se defina enquanto tal é preciso um constraste permanente com o profano a fim de que uma diferença qualitativa se instaure e que cada qual, por oposição, se estabeleça. Mesmo na igreja, no topo do rochedo, onde se encontra a imagem da santa, o "sagrado do sagrado", a oposição está presente: através da presença dos romeiros diante da santa, que representariam o profano diante do sagrado, a oposição se reinstaura.

Neste sentido, se a espacialidade da Festa da Penha é um momento privilegiado do estebelecimento de relações entre o sagrado e o profano, estas se dão em forma de oposição complementar, pois vemos que em todos os momentos, ou melhor, em todos os planos da festa, ambos se fazem presentes. Recuperando a

concepção durkheimiana, poderíamos dizer que para que o sagrado se torne identificável, é preciso que ele esteja em uma relação de oposição com o profano, pois é a partir desse contraste que ambos se constituem.

\section{NOTAS}

1 Professora adjunta do Departamento de Antropologia do Museu Nacional e do Programa de Pós-Graduação em Antropologia Social, Universidade Federal do Rio de Janeiro. Currículo Lattes: http://lattes.cnpq.br/0362564363969147.

${ }^{1} \mathrm{Na}$ verdade, apaixonei-me pela Antropologia justamente ao fazer como ouvinte um curso sobre "Tempo e Espaço, ministrado pela professora Lygia Sigaud, no Museu Nacional, no segundo semestre de 1987. Recém-graduada em história, fiquei encantada pelos textos, que abordavam as várias formas de relação dos grupos sociais com o tempo e o espaço, discutindo a diversidade de temporalidades, de formas de contagem do tempo, de expressões da organização social em espaços culturalmente apropriados.

1 Trata-se de uma analogia com a noção de gramática gerativa de Noam Chomsky, "uma teoria que discute aspectos linguísticos como a criatividade do falante e a sua capacidade de emitir e de compreender frases inéditas. Sendo assim, a gramática seria considerada um sistema finito que permite gerar um conjunto infinitos de frases gramaticais" (http://www.infoescola.com/linguistica/gramatica-gerativa/. Acesso em: 14 fev. 2012).

${ }^{1} \mathrm{O}$ "clássico" como aqui referido não deve ser entendido como um cânone inquestionável, ou como algo essencializado, mas como uma obra que opera como referencial comum para uma determinada 
comunidade acadêmica, marcando a adesão ao próprio grupo. São clássicos, portanto, os textos de estatuto privilegiado que condensam questões, ou apresentam uma capacidade peculiar de definir parâmetros e de oferecer certa exemplaridade enquanto um modelo de pesquisa. (Para uma discussão mais detalhada a respeito, ver MENEZES, 2009)

${ }^{1}$ Trata-se de uma pesquisa realizada em uma festa de santo católica do subúrbio carioca ainda nos anos 1990, que resultou em minha dissertação de mestrado (Menezes, 1996) e que estou tentando reativar desde 2011, como veremos em detalhe na seção III

${ }^{1}$ Franz Boas, considerado um dos fundadores da antropologia, fo especialista em línguas e culturas dos indígenas americanos. Ele estudou física e geografia em Heidelberg; fez $\mathrm{Ph}$. D. na Universidade de Kiel (1881), e desenvolveu interesse pela relação entre as sensações físicas e a percepção psicológica. Mais tarde, em uma expedição científica à Ilha de Baffin, no Canadá (1883-1884), junto aos esquimós (os inuit), passou a se interessar pelas "culturas primitivas"

${ }^{1}$ Não o animismo, isto é, a crença em seres espirituais, como Edward Tylor; nem o naturismo, isto é, a crença em forças da natureza assimiláveis a atos humanos defendida por Max Muller, ambos teóricos de peso à época.

${ }^{1}$ O Ramo Dourado é uma obra em 12 volumes elaborada de 1899 a 1915, na qual o autor faz um estudo comparativo dos mitos e do folclore de várias sociedades, defendendo a tese de que o pensamento humano evoluiu de um estágio mágico para o religioso, e daí para o científico. Apesar do tamanho, a obra conheceu enorme sucesso tendo uma versão condensada editada em 1922, na qual se baseia a tradução brasileira.

${ }^{1}$ No ano de 2011, a festa encontrava-se bastante esvaziada, tanto por conta da supremacia de outras formas de lazer como por dinâmicas do campo religioso, com o crescimento evangélico massivo na cidade do Rio de Janeiro, e ainda pela questão da violência relacionada ao tráfico de drogas na região da Igreja ponto.

${ }^{1}$ Para análises detalhadas e complexas da história da festa, consultar Menezes, 1996; 2012

${ }^{1}$ Diz Mauss: "Nesses fenômenos sociais "totais" (...) exprimem-se, de uma só vez, as mais diversas instituições: religiosas, jurídicas e morais - estas sendo políticas e familiares ao mesmo tempo - econômicas estas supondo formas particulares de produção e do consumo, ou melhor, do fornecimento e da distribuição - sem contar os fenômenos estéticos em que resultam esses fatos e os fenômenos morfológico que essas instituições manifestam". (MAUSS, 2003, p. 187).

${ }^{1} \mathrm{Na}$ verdade, apaixonei-me pela Antropologia justamente ao faze como ouvinte um curso sobre "Tempo e Espaço, ministrado pela professora Lygia Sigaud, no Museu Nacional, no segundo semestre de 1987. Recém-graduada em história, fiquei encantada pelos textos, que abordavam as várias formas de relação dos grupos sociais com o tempo e o espaço, discutindo a diversidade de temporalidades, de formas de contagem do tempo, de expressões da organização socia em espaços culturalmente apropriados.

1 Trata-se de uma analogia com a noção de gramática gerativa de Noam Chomsky, "uma teoria que discute aspectos linguísticos como a criatividade do falante e a sua capacidade de emitir e de compreender frases inéditas. Sendo assim, a gramática seria considerada um sistema finito que permite gerar um conjunto infinitos de frases gramaticais" (http://www.infoescola.com/linguistica/gramatica-gerativa/. Acesso em: 14 fev. 2012)
1 O "clássico" como aqui referido não deve ser entendido como um cânone inquestionável, ou como algo essencializado, mas como uma obra que opera como referencial comum para uma determinada comunidade acadêmica, marcando a adesão ao próprio grupo. São clássicos, portanto, os textos de estatuto privilegiado que condensam questões, ou apresentam uma capacidade peculiar de definir parâmetros e de oferecer certa exemplaridade enquanto um modelo de pesquisa. (Para uma discussão mais detalhada a respeito, ver MENEZES, 2009)

${ }^{1}$ Trata-se de uma pesquisa realizada em uma festa de santo católica do subúrbio carioca ainda nos anos 1990, que resultou em minha dissertação de mestrado (Menezes, 1996) e que estou tentando reativar desde 2011, como veremos em detalhe na seção III.

${ }^{1}$ Franz Boas, considerado um dos fundadores da antropologia, foi especialista em línguas e culturas dos indígenas americanos. Ele estudou física e geografia em Heidelberg; fez $\mathrm{Ph}$. D. na Universidade de Kiel (1881), e desenvolveu interesse pela relação entre as sensações físicas e a percepção psicológica. Mais tarde, em uma expedição científica à Ilha de Baffin, no Canadá (1883-1884), junto aos esquimós (os inuit), passou a se interessar pelas "culturas primitivas".

${ }^{1}$ Não o animismo, isto é, a crença em seres espirituais, como Edward Tylor; nem o naturismo, isto é, a crença em forças da natureza assimiláveis a atos humanos defendida por Max Muller, ambos teóricos de peso à época.

${ }^{1}$ O Ramo Dourado é uma obra em 12 volumes elaborada de 1899 a 1915, na qual o autor faz um estudo comparativo dos mitos e do folclore de várias sociedades, defendendo a tese de que o pensamento humano evoluiu de um estágio mágico para o religioso, e daí para o científico. Apesar do tamanho, a obra conheceu enorme sucesso, tendo uma versão condensada editada em 1922, na qual se baseia a tradução brasileira.

${ }^{1}$ No ano de 2011, a festa encontrava-se bastante esvaziada, tanto por conta da supremacia de outras formas de lazer como por dinâmicas do campo religioso, com o crescimento evangélico massivo na cidade do Rio de Janeiro, e ainda pela questão da violência relacionada ao tráfico de drogas na região da Igreja ponto.

${ }^{1}$ Para análises detalhadas e complexas da história da festa, consultar Menezes, 1996; 2012.

${ }^{1}$ Diz Mauss: "Nesses fenômenos sociais "totais" (...) exprimem-se, de uma só vez, as mais diversas instituições: religiosas, jurídicas e morais - estas sendo políticas e familiares ao mesmo tempo - econômicas estas supondo formas particulares de produção e do consumo, ou melhor, do fornecimento e da distribuição - sem contar os fenômenos estéticos em que resultam esses fatos e os fenômenos morfológicos que essas instituições manifestam". (MAUSS, 2003, p. 187).

\section{REFERÊNCIAS BIBLIOGRÁFICAS}

ALEXANDER, Jeffrey C. A importância dos clássicos. In: GIDDENS, A.; TURNER, J. Teoria Social Hoje. São Paulo: Unesp, 1999, p. 23-89

DURKHEIM, Émile. As Formas Elementares da Vida Religiosa (o sistema totêmico na Austrália). São Paulo: Edições Paulinas, 1989 [1912].

DURKHEIM, Émile; MAUSS, Marcel. Algumas formas primitivas de classificação. Contribuição para o estudo das representações coletivas. 
In: MAUSS, Marcel. Ensaios de Sociologia. São Paulo: Perspectiva, 1981 [1903], p. 399-455.

FRAZER, James G. O ramo de ouro. São Paulo: Circulo do Livro, 1978 [1890-1915; 1922].

HERTZ, Robert: A preeminência da mão direita. Religião $e$ Sociedade (6), p. 99-128, 1980 [1909].

HUBERT, Henri. Étude sommaire de la representation du temps dans la religion et la magie. In: Mélanges d'Histoire des Religions Paris: Félix Alcan, 1929 [1905], p. 189-229.

HUBERT, Henry; MAUSS, Marcel. Sobre o sacrifício. São Paulo: Cosac Naify, 2005 [1899].

LAPLANTINE, François. Aprender Antropologia. São Paulo: Brasiliense, 1987.

LARAIA, Roque de Barros. Cultura: um conceito antropológico. V5 Ed. Rio de Janeiro: Jorge Zahar Editor, 1989

MAUSS, Marcel; HUBERT, Henry. Esboço de uma teoria geral da magia. In: MAUSS, Marcel, Sociologia e Antropologia. São Paulo: Cosac \& Naify, 2003 [1902-3], p. 47-181.

MAUSS, Marcel. La prière. In: Oeuvres. V. 1: Paris: Minuit, 1968 [1909], p. 357-477.

Ensaio sobre a Dádiva. In: Sociologia
MASUZAWA, Tomoko. The Invention of World Religions. Chicago London: The University of Chicago Press, 2005.

MENEZES, Renata de Castro. Permanências e Mudanças na Festa da Penha, Rio de Janeiro. In: SOUZA, Rolf Malungo de (org.). $O$ fenômeno suburbano. Rio de Janeiro: Dígrafo, 2012.

Celebrando São Besso ou o que Robert Hertz e a Escola Francesa de Sociologia têm a nos dizer sobre festas, rituais e simbolismo. Religião \& Sociedade, 29 (1), p. 179-199, 2009.
Devoção e diversão: a Festa da Penha (RJ) como uma romaria. Revista Eclesiástica Brasileira, v. 60, n.238, p. 312-340, 2000 . Devoção, diversão e poder: um estudo antropológico sobre a

Festa da Penha. 1996, 158 f, Dissertaçao de Mestrado (Antropologia Social), Programa de Pós-Graduação em Antropologia Social, Museu Nacional, Universidade Federal do Rio de Janeiro, 1996.

POMPA, Cristina. Para uma antropologia histórica das missões. In: MONTERO, Paula (org.). Deus na Aldeia. São Paulo: Globo, 2006, p. $111-142$.

SMITH, Jonathan Z. Religion, Religions, Religious. In: TAYLOR, Mark C. (ed.) Critical Terms for Religious Studies. Chicago, London: University of Chicago Press, 1998, p. 269-284.

SMITH. William Robertson The religion of the Semites: the fundamental institutions._New York : Schocken Books, 1972 [1889].

TYLOR, Edward B. Primitive Culture. Cambridge: Cambridge University Press, 2010 [1871] 
SPACE, RELIGION \& ANTHROPOLOGY: A READING OF THE ELEMENTARY FORMS OF RELIGIOUS LIFEBY DURKHEIM

ABSTRACT: THE PAPER PRESENTS A DISCUSSION ABOUT RELIGION AND SPACE FROM AN ANTHROPOLOGICAL PERSPECTIVE, TAKING AS GUIDING AN ANALYSIS OF THE ELEMENTARY FORMS OF RELIGIOUS LIFE, BY EMILE DURKHEIM, BOTH IN THE CONTEXT OF THEIR CREATION IN THE EARLY TWENTIETH CENTURY, AS IN THEIR APPLICATION POSSIBILITIES IN CONTEMPORARY RESEARCH.

KEY-WORDS: RELIGION, SPACE AND ANTHROPOLOGY, FRENCH SOCIOLOGICAL SCHOOL, DURKHEIM, SPACE AND SOCIABILITY, SPACE AND CLASSIFICATION. 
$+2$ 